\title{
The venous-arterial partial pressure of carbon dioxide as a new monitoring of circulatory disorder: no so simple
}

\author{
J. P. Viale ${ }^{1}$
}

Published online: 1 April 2016

(C) Springer Science+Business Media Dordrecht 2016

Restoring or maintaining an optimal oxygen supply adjusted to oxygen demand remains the key aim of all clinicians facing a circulatory dysfunction, whatever the cause. Many therapeutic tools are available, ranging from adequate fluid resuscitation, cardio or vaso-active agents, to adjuvant therapies and various ventilatory supports. Most of the challenges for clinicians are the choice of therapeutics, their dosage, and management of their potential interactions. In addition, in the course of circulatory distress, it would be of great help to identify patients at risk of developing organ dysfunction, in order to intensify and adapt treatment of such individuals. As a guide to achieve these purposes, normalisation of mixed venous oxygen saturation and blood lactate has been proposed as endpoint resuscitations but revealed unsuccessful in several clinical studies [1-3]. The monitoring of the mixed venous-arterial gradient in partial pressure of carbon dioxide $\left[\mathrm{p}(\mathrm{mv}-\mathrm{a}) \mathrm{CO}_{2}\right]$ has been recently put forward and revealed promising. A high $\mathrm{CO}_{2}$ gradient would indicate an inadequate organ perfusion and a risk of delayed organ dysfunction. Have we reached a satisfactory answer to a main clinical question?

In this issue Morel et al. [4] retrospectively analysed 220 consecutive patients admitted in intensive care unit after an elective cardiac surgery. Monitoring $\mathrm{p}(\mathrm{mv}-\mathrm{a}) \mathrm{CO}_{2}$, they observed at the 6th postoperative hour a group of 55 patients having a gradient greater than $6 \mathrm{~mm} \mathrm{Hg}$. Surprisingly and contrary to previous published results, these patients experienced a lower SOFA score, hospital and 6 month mortality. The authors concluded that in this

\footnotetext{
$\square$ J. P. Viale

jean-paul.viale@univ-lyon1.fr

1 Université de Lyon, 69008 Lyon, France
}

clinical setting, the $\mathrm{CO}_{2}$ gradient is not predictive of poor outcome. This apparently paradoxical results is on line with other works underlying the poor discriminative value of the gradient [5]. Rather than the premature conclusion of a promising story, this is more likely a plea to gain more insight in our knowledge about a complex indicator.

The $\mathrm{p}(\mathrm{mv}-\mathrm{a}) \mathrm{CO}_{2}$ is the difference between two partial pressures of $\mathrm{CO}_{2}$ : the mixed venous and the arterial. The normal value is commonly held as lower than $6 \mathrm{~mm} \mathrm{Hg}$. The venous pressure depends on several components, the content of mixed venous in $\mathrm{CO}_{2}$, and the relationship between the concentration and the pressure. The content itself is a concentration, that is to say the ratio of the amount of $\mathrm{CO}_{2}$ driven from peripheral organs to the amount of blood arising from the same organs or segments of organs. The arterial pressure depends on the lung function and is strictly proportional to the alveolar ventilation. Given a constant alveolar ventilation, this arterial pressure remains stable provided that the venous pressure is not modified. If an increase in mixed venous $\mathrm{pCO}_{2}$ occurs, the amount of $\mathrm{CO}_{2}$ exhaled by the lung will increase, enlarging the venous-arterial gradient. This role of the lung is schematically illustrated by the increase in end-tidal partial pressure of $\mathrm{CO}_{2}$ occurring soon after the release of a tourniquet. Any small increase in the arterial side would induce an increase in alveolar ventilation in patient having the ability to spontaneously regulate for acid basic equilibrium disturbance. The main factors of variation of the gradient are therefore on the mixed venous side.

- The relationship between the concentration and pressure is complex. Although less pronounced than for oxygen, it is curvilinear over the full range of $\mathrm{pCO}_{2}$ but almost linear for the physiological one. More importantly, this relationship is influenced by acido basic 
equilibrium, oxygen saturation, temperature and haematocrit. Acidosis is the major factor inducing a higher $\mathrm{pCO}_{2}$ for a same concentration. Oxygen desaturation has the opposite effect (Haldane effect). Other factors are of minor amplitude.

- The mixed venous $\mathrm{CO}_{2}$ concentration has two major components.

- The first one is the cardiac output, necessary to convey $\mathrm{CO}_{2}$ to the lung. For a fixed amount of $\mathrm{CO}_{2}$ driven from peripheral organs, any decrease in cardiac output would induce an increase in the concentration gradient and therefore the pressure gradient. The relationship is curvilinear with a convex downward configuration, the induced variation of gradient being larger for low values of cardiac output [6].

- The second is not simple to figure out. It is the amount of $\mathrm{CO}_{2}$ generated by peripheral organ and washed out by the microcirculation. In steady state conditions, this amount is equal to the carbon dioxide production, no storage or release of $\mathrm{CO}_{2}$ occurring in the organ, and all $\mathrm{CO}_{2}$ being conveyed to the lung. It is therefore strictly parallel to the oxygen consumption multiplied by the respiratory quotient. On the other hand, the $\mathrm{CO}_{2}$ generated by organs could deviate from the oxygen consumption in several clinical contexts [7].

- When circulation is lacking no $\mathrm{CO}_{2}$ arises from the blood flow deprived organ, and $\mathrm{CO}_{2}$ accumulates, venous $\mathrm{PCO}_{2}$ decreases. This stored $\mathrm{CO}_{2}$ would be eventually washed out in case of restoration of circulation, inducing an increase in venous $\mathrm{pCO}_{2}$. This behaviour for $\mathrm{CO}_{2}$ holds true for an absolute lack of flow. This is scarcely encountered in clinical practice, reserved to vascular clamping episodes or tourniquet placements.

- In most of the clinical disorders such as septic shock, haemorrhage, traumatic injuries, or surgery induced organ dysfunction, the pivotal events of pathogenesis lies in the microcirculatory disorder. This later is characterized by a microvascular perfusion heterogeneity impairing the oxygen diffusion to tissues. Contrary to oxygen, $\mathrm{CO}_{2}$ is much more soluble and able to diffuse back from hypoxic cells to microvascular vessels remaining perfused, reaching the effluent veins. Therefore, $\mathrm{CO}_{2}$ is able to be measured in the mixed venous blood in case of microvascular disorder, evidencing blood stagnation. The slow flow as well as the local acidosis by its effect on the $\mathrm{CO}_{2}$ dissociation curve is likely to further increase the partial pressure of $\mathrm{CO}_{2}$. To this description of $\mathrm{CO}_{2}$ washout, the adaptive mechanism of anaerobic metabolism should be added. During acidosis associated to anaerobic metabolism, $\mathrm{CO}_{2}$ production exceeds the linked oxygen consumption, due to the buffering of $\mathrm{H}+$ by bicarbonates. However, the amount of $\mathrm{CO}_{2}$ arising from anaerobic production is low, and not able to compensate for the decrease metabolic $\mathrm{CO}_{2}$ production linked to the oxygen delivery dependent decrease in oxygen consumption. As a whole, regarding the evolution of microvascular venous blood, there is a paradoxical opposition between $\mathrm{CO}_{2}$ and oxygen during microvascular disorder: $\mathrm{pCO}_{2}$ is increased whereas partial pressure of $\mathrm{O}_{2}$ is not concomitantly decreased. Therefore the $\mathrm{CO}_{2}$ emerging from peripheral organ could not be considered as an indicator of tissue oxygen consumption, but rather as an index of remaining functional microcirculation washing out the cellular production of $\mathrm{CO}_{2}$.

- Considering the above described venous $\mathrm{pCO}_{2}$ behaviour in microvascular disorder with low local blood flow, the opposite should hold true when the local blood flow is preserved, despite a limited tissue oxygen availability. The anaerobic production of $\mathrm{CO}_{2}$ does not compensate for the decrease of aerobic production, and moreover the preserved blood flow is able to clear the produced $\mathrm{CO}_{2}$. Therefore, the venous $\mathrm{pCO}_{2}$ and thus the $\mathrm{p}(\mathrm{mv}-\mathrm{a}) \mathrm{CO}_{2}$ is not expected to increase. Such clinical situations of a tissue limited oxygen consumption with a preserved blood flow are likely to be less common, resulting from deep hypoxia from respiratory cause, or sepsis induced mitochondrial dysfunction in resuscitated septic shock. In this case, a normal value of $\mathrm{p}(\mathrm{mv}-\mathrm{a}) \mathrm{CO}_{2}$ could not rule out any oxygen debt building up.

If all the components of the $\mathrm{p}(\mathrm{mv}-\mathrm{a}) \mathrm{CO}_{2}$ have been set up as individual factors for the sake of clarity, in the actual life they are brought into play in a combined interplay. The final result on $\mathrm{p}(\mathrm{mv}-\mathrm{a}) \mathrm{CO}_{2}$ is not only dependent on the direction and amplitude of each factor, but also on the time dependency of each of them. Therefore the analysis of $\mathrm{p}(\mathrm{mv}-\mathrm{a}) \mathrm{CO}_{2}$ variation could not be straightforward but implies a true physio pathological thinking. The clinical situations listed below are to illustrate some reflexions about $\mathrm{p}(\mathrm{mv}-\mathrm{a}) \mathrm{CO}_{2}$.

- Studying $\mathrm{p}(\mathrm{mv}-\mathrm{a}) \mathrm{CO}_{2}$ during hypoxia is a mean to analyse the respective roles of venous return and metabolic production of $\mathrm{CO}_{2}$. Experimental studies on isolated limb [8] or small intestine mucosa [9], and 
further confirmed by theoretical mathematical models of $\mathrm{CO}_{2}$ exchange during hypoxia [10] show that venous $\mathrm{pCO}_{2}$ evolutions are different during ischemic and hypoxic hypoxia. The authors observed venous $\mathrm{pCO}_{2}$ kinetics when reducing oxygen delivery beyond the critical threshold value while oxygen consumption becomes dependent on oxygen delivery. The rise in venous $\mathrm{pCO}_{2}$ was larger when decrease in oxygen delivery was induced by a reduction of blood flow (ischemic hypoxia) compared to a reduction of oxygen content (hypoxic hypoxia) with a maintained blood flow. This difference in both types of hypoxia occurred despite a similar reduction in tissue oxygen consumption and $\mathrm{CO}_{2}$ production. The anaerobic production of $\mathrm{CO}_{2}$ occurring in both types of hypoxia is not large enough to induce a same enlargement of $\mathrm{p}(\mathrm{mv}-\mathrm{a}) \mathrm{CO}_{2}$. Consistent with the pathophysiological behaviour of $\mathrm{CO}_{2}$ and oxygen kinetics cited above, these results emphasize one of the major strength and linked weakness of $\mathrm{p}(\mathrm{mv}-\mathrm{a}) \mathrm{CO}_{2}$ : any increase is not an index of the amplitude of dysoxia due to lack of oxygen availability, but rather a marker of persisting vascular hypo perfusion. In other words, a lack of $\mathrm{p}(\mathrm{mv}-\mathrm{a}) \mathrm{CO}_{2}$ enlargement does not preclude any tissue dysoxia, on the other hand a high $\mathrm{p}(\mathrm{mv}-\mathrm{a}) \mathrm{CO}_{2}$ indicates a poor organ perfusion relative to its demand.

- The role of $\mathrm{p}(\mathrm{mv}-\mathrm{a}) \mathrm{CO}_{2}$ as marker during septic shock has been extensively evaluated [7, 11] and is illustrative of the above mentioned limitations. Most of the authors observed in septic shock an increased $\mathrm{p}(\mathrm{mv}-\mathrm{a}) \mathrm{CO}_{2}$, largely ascribed to a reduced systemic or microvascular blood flow [12-15]. A poor prognosis was usually linked to this increase. More interestingly, this gradient remained enlarged even in patients with a normal mixed venous oxygen saturation $\left(\mathrm{ScvO}_{2}\right)$ [14]. Using video microscopic imaging, Ospina-Tascon et al. [16] were able to show that patients experiencing a large $\mathrm{p}(\mathrm{mv}-\mathrm{a}) \mathrm{CO}_{2}$ despite a normal value of $\mathrm{ScvO}_{2}$ had lower functional capillary density and higher heterogeneity of microvascular blood flow. From a clinical point of view, Vallée et al. [12] found that this group of patients had a lower lactate clearance and higher SOFA score $24 \mathrm{~h}$ after the gradient measurement. These findings are of value for assessing patients who could benefit of a more aggressive and persistent treatment of microcirculatory failure.

- Using the $\mathrm{p}(\mathrm{mv}-\mathrm{a}) \mathrm{CO}_{2}$ in the surgical setting in order to identify patients at risk of developing postoperative complications emphasizes the key point of the time dependency of markers. Most of the studies addressing the issue of $\mathrm{p}(\mathrm{mv}-\mathrm{a}) \mathrm{CO}_{2}$ in the postoperative period of high risk surgery found a greater gradient in patients undergoing postoperative complications [17, 18]. In addition, the relationship between gradient and complications was still observed in the sub-group of patients with a normal $\mathrm{ScvO}_{2}$. It is noteworthy that these results depend on the time of the gradient sampling. For example, in the Robin's study, this gradient was significantly different between complicated and non-complicated patients at admission in intensive care unit, but tended to subsequently decrease. In the Morel's [4] study, the number of patients having a high gradient was greater at 6th postoperative hour. It is likely that the circulatory management brought into play to the high risk patients may rapidly modify the gradient whereas the tissue insult induced by the microvascular disorder is still an ongoing process. The gradient measurement may therefore miss the potential tissue damage. The time dependency is also an issue on the arterial side of the gradient. Any increase in alveolar ventilation will decrease the arterial $\mathrm{pCO}_{2}$, but in a time dependent way. Contrary to oxygen, owing to its higher solubility the store of body $\mathrm{CO}_{2}$ is huge, approximately $120 \mathrm{~L}$ for an adult. An increase in alveolar ventilation will result in a wash out of a fraction of the stores before reaching a new equilibrium. Therefore, the arterial $\mathrm{pCO}_{2}$ will be stable only after 20 or 30 min have elapsed, precluding any gradient sampling during this period. The effect of the $\mathrm{CO}_{2}$ storage could play a role on the venous side. However, the clinical events range largely over the time necessary to reach equilibrium, and therefore any sampling caution should be reserved to change in mechanical alveolar ventilation.

Keeping in mind the above mentioned limitations, some recent propositions are likely to simplify and extend the use of the $\mathrm{p}(\mathrm{mv}-\mathrm{a}) \mathrm{CO}_{2}$.

- The measurement of central venous $\mathrm{pCO}_{2}$ as a surrogate of mixed venous $\mathrm{pCO}_{2}$ would simplify the procedure. Several studies indicate that the correlation of gradient measured from both sites are well correlated with cardiac output [19, 20], both values have good agreement [13], and central venous measured gradient is useful in identifying inadequately resuscitated [12] or poor outcome patients [13] in septic shock.

- As suggested by the interesting difference between oxygen and carbon dioxide derived parameters as markers of microcirculatory disorders, the combination of both indices could enhanced their clinical use. Two ways are available. The first one is to use markers in a successive sequence: once the normal value of $\mathrm{ScvO}_{2}$ is achieved, the use of the $\mathrm{p}(\mathrm{mv}-\mathrm{a}) \mathrm{CO}_{2}$ could identify patients still remaining with a microvascular sepsis induced disorder [7, 12, 17]. On the other hand, combined parameters have been proposed. The ratio of 
$\mathrm{CO}_{2}$ to oxygen derived indices have been proposed as content or pressure gradients. They have been found to be reliable markers of anaerobic metabolism in septic shock [21, 22], even in the presence of normalized mean arterial pressure and $\mathrm{ScvO}_{2}$ [23], and to be an independent marker of mortality in septic shock [24].

As a whole, after enthusiastic initial reports, the $\mathrm{p}(\mathrm{mv}-$ a) $\mathrm{CO}_{2}$ follows the classical history of all new biological markers. It revealed more complex as initially thought, the role of the clinical research is to help the clinician to deepen its meaning and accurately defined its use. Among the critical issues that need more insight: turning the binary value of $\mathrm{p}(\mathrm{mv}-\mathrm{a}) \mathrm{CO}_{2}$, normal-abnormal, as a more gradual one, describing its temporal pattern in the postoperative period, refining its role as a marker of persisting microvascular disturbance despite a normalized $\mathrm{ScvO}_{2}$, its meaning during shock with preserved blood flow, and the relevant place of the combined $\mathrm{CO}_{2}$ and $\mathrm{O}_{2}$ derived markers. Before being proposed in routine clinical practice, the understanding of this gradient needs to be strengthened by additional clinical research by using microcirculation imaging and validated by large clinical trials.

\section{References}

1. Bellomo R, Reade MC, Warrillow SJ. The pursuit of a high central venous oxygen saturation in sepsis: growing concerns. Crit Care. 2008;12:130.

2. Perel A. Bench-to-bedside review: the initial hemodynamic resuscitation of the septic patient according to Surviving Sepsis Campaign guidelines-Does one size fit all? Crit Care. 2008;12:223.

3. Angus DC, Barnato AE, Bell D, Bellomo R, Chong C-R, Coats TJ, et al. A systematic review and meta-analysis of early goaldirected therapy for septic shock: the ARISE, ProCESS and ProMISe Investigators. Intensive Care Med. 2015;41:1549-60.

4. Morel J, Grand N, Axiotis G, Bouchet JB, Faure M, Auboyer C, et al. High veno-arterial carbon dioxide gradient is not predictive of worst outcome after an elective cardiac surgery: a retrospective cohort study. J Clin Monit Comput. 2016. doi:10.1007/s10877016-9855-3.

5. Lebuffe G, Levy B, Nevière R, Chagnon J-L, Perrigault P-F, Duranteau J, et al. Dobutamine and gastric-to-arterial carbon dioxide gap in severe sepsis without shock. Intensive Care Med. 2002;28:265-71.

6. Dash RK, Bassingthwaighte JB. Blood $\mathrm{HbO} 2$ and $\mathrm{HbCO} 2$ dissociation curves at varied $\mathrm{O} 2, \mathrm{CO} 2, \mathrm{pH}, 2,3-\mathrm{DPG}$ and temperature levels. Ann Biomed Eng. 2004;32:1676-93.

7. Mallat J, Lemyze M, Tronchon L, Vallet B, Thevenin D. Use of venous-to-arterial carbon dioxide tension difference to guide resuscitation therapy in septic shock. World J Crit Care Med. 2016;5:47-56.

8. Vallet B, Teboul JL, Cain S, Curtis S. Venoarterial CO(2) difference during regional ischemic or hypoxic hypoxia. J Appl Physiol. 2000;89:1317-21.

9. Nevière R, Chagnon J-L, Teboul J-L, Vallet B, Wattel F. Small intestine intramucosal $\mathrm{PCO}(2)$ and microvascular blood flow during hypoxic and ischemic hypoxia. Crit Care Med. 2002;30:379-84.
10. Gutierrez G. A mathematical model of tissue-blood carbon dioxide exchange during hypoxia. Am J Respir Crit Care Med. 2004;169:525-33.

11. Naumann DN, Midwinter MJ, Hutchings S. Venous-to-arterial $\mathrm{CO}_{2}$ differences and the quest for bedside point-of-care monitoring to assess the microcirculation during shock. Ann Transl Med. 2016;4:37.

12. Vallée F, Vallet B, Mathe O, Parraguette J, Mari A, Silva S, et al. Central venous-to-arterial carbon dioxide difference: an additional target for goal-directed therapy in septic shock? Intensive Care Med. 2008;34:2218-25.

13. van Beest PA, Lont MC, Holman ND, Loef B, Kuiper MA, Boerma EC. Central venous-arterial $\mathrm{pCO}_{2}$ difference as a tool in resuscitation of septic patients. Intensive Care Med. 2013;39: 1034-9.

14. Mallat J, Pepy F, Lemyze M, Gasan G, Vangrunderbeeck N, Tronchon L, et al. Central venous-to-arterial carbon dioxide partial pressure difference in early resuscitation from septic shock: a prospective observational study. Eur J Anaesthesiol. 2014;31:371-80.

15. Bakker J, Vincent JL, Gris P, Leon M, Coffernils M, Kahn RJ Veno-arterial carbon dioxide gradient in human septic shock. Chest. 1992;101:509-15.

16. Ospina-Tascón GA, Bautista-Rincón DF, Umaña M, Tafur JD, Gutiérrez A, García AF, et al. Persistently high venous-to-arterial carbon dioxide differences during early resuscitation are associated with poor outcomes in septic shock. Crit Care. 2013;17: R294.

17. Futier E, Robin E, Jabaudon M, Guerin R, Petit A, Bazin J-E, et al. Central venous $\mathrm{O}_{2}$ saturation and venous-to-arterial $\mathrm{CO}_{2}$ difference as complementary tools for goal-directed therapy during high-risk surgery. Crit Care. 2010;14:R193.

18. Robin E, Futier E, Pires O, Fleyfel M, Tavernier B, Lebuffe G, et al. Central venous-to-arterial carbon dioxide difference as a prognostic tool in high-risk surgical patients. Crit Care. 2015; 19:227.

19. Tsaousi GG, Karakoulas KA, Amaniti EN, Soultati ID, Zouka MD, Vasilakos DG. Correlation of central venous-arterial and mixed venous-arterial carbon dioxide tension gradient with cardiac output during neurosurgical procedures in the sitting position. Eur J Anaesthesiol. 2010;27:882-9.

20. Cuschieri J, Rivers EP, Donnino MW, Katilius M, Jacobsen G, Nguyen HB, et al. Central venous-arterial carbon dioxide difference as an indicator of cardiac index. Intensive Care Med. 2005;31:818-22.

21. Mallat J, Lemyze M, Meddour M, Pepy F, Gasan G, Barrailler S, et al. Ratios of central venous-to-arterial carbon dioxide content or tension to arteriovenous oxygen content are better markers of global anaerobic metabolism than lactate in septic shock patients. Ann Intensive Care. 2016;6:10.

22. Mekontso-Dessap A, Castelain V, Anguel N, Bahloul M, Schauvliege F, Richard C, et al. Combination of venoarterial $\mathrm{PCO}_{2}$ difference with arteriovenous $\mathrm{O}_{2}$ content difference to detect anaerobic metabolism in patients. Intensive Care Med. 2002;28:272-7.

23. Mesquida J, Saludes P, Gruartmoner G, Espinal C, Torrents E, Baigorri $\mathrm{F}$, et al. Central venous-to-arterial carbon dioxide difference combined with arterial-to-venous oxygen content difference is associated with lactate evolution in the hemodynamic resuscitation process in early septic shock. Crit Care. 2015; 19:126

24. Ospina-Tascón GA, Umaña M, Bermúdez W, Bautista-Rincón DF, Hernandez G, Bruhn A, et al. Combination of arterial lactate levels and venous-arterial $\mathrm{CO}_{2}$ to arterial-venous $\mathrm{O}_{2}$ content difference ratio as markers of resuscitation in patients with septic shock. Intensive Care Med. 2015;41:796-805. 